\title{
Analysis of tank safety with propane-butane on LPG distribution station
}

\author{
Zbigniew Krzysiak $^{1}$, Waldemar Samociuk ${ }^{1}$, Grzegorz Bartnik $^{1}$, Krzysztof Plizga ${ }^{1}{ }^{*}$, Dariusz Dziki ${ }^{1}$, \\ Zdzisław Kaliniewicz ${ }^{2}$, Aleksander Nieoczym ${ }^{3}$, Aleksander Wyciszkiewicz ${ }^{4}$, Tomasz Otto ${ }^{4}$ \\ ${ }^{1}$ University of Life Sciences in Lublin, Akademicka 13 str., 20-950 Lublin, Poland \\ ${ }^{2}$ University of Warmia and Mazury in Olsztyn, Oczapowskiego 2 str., 10-719 Olsztyn, Poland \\ ${ }^{3}$ Lublin University of Technology, Nadbystrzycka 38 D str., 20-618 Lublin, Poland \\ ${ }^{4}$ Silesian University of Technology, Akademicka 2 A str., 44-100 Gliwice, Poland \\ "Corresponding author: e-mail: krzysztof.plizga@up.lublin.pl
}

\begin{abstract}
An analysis of the risk of failure in the safety valve - tank with propane-butane (LPG) system has been conducted. An uncontrolled outflow of liquid LPG, caused by a failure of the above mentioned system has been considered as a threat. The main research goal of the study is the hazardous analysis of propanebutane gas outflow for the safety valve - LPG tank system. The additional goal is the development of an useful method to fast identify the hazard of a mismatched safety valve. The results of the research analysis have confirmed that safety valves are basic protection of the installation (tank) against failures that can lead to loss of life, material damage and further undesired costs of their unreliability. That is why a new, professional computer program has been created that allows for the selection of safety valves or for the verification of a safety valve selection in installations where any technical or technological changes have been made.
\end{abstract}

Keywords: safety valve, risk analysis, emergency scenarios, LPG.

\section{INTRODUCTION}

The development of means of transport using liquid and gaseous fuels resulted in the need for continuous access to these kinds of fuels. It forced coming into existence a network of potentially dangerous objects such as petrol stations. Along with technological progress, petrol stations security level increases, which means a reduction of environmental threats. However, there is not possible complete elimination of the risks resulting from the working of the objects located on the petrol stations (i.e. gas tanks), and the security level depends mainly on the reliability of safety devices.

Storage and distribution of synthetic gas has numerous threats to human health and life, as well as to the natural environment ${ }^{1}$, because it is a poisonous, harmful and flammable substance. Gas tanks pose a high probability of the explosive atmospheres occurrence ${ }^{2}$.

Therefore, it was necessary to develop such mechanisms (technical and logistical) to reduce risk. This is also required by the legal system and controls of the Office of Technical Inspection (UDT), which force the owners of LPG stations to maintain an appropriate level of security.

In order to increase security, risk as a base to determine the most important ways to its reduction is analyzed ${ }^{3-5}$. A common method is an analysis of two types of scenarios: emergency ${ }^{6}$ of the hazardous effects and these with the greatest probability of their occurrence.

The security system should take into account, among others, introduction of the solutions enabling systematic analysis of failure risk and analysis of the likelihood of their occurrence. It is worth to focus on the ability to create and use reliability models for systems equipped with tanks containing propane-butane, and the ability to collect their diagnostic signals, as well as other technical facilities $^{7,8}$.In this case, the most appropriate method of reliability modeling are Bayesian networks, whose nodes represent occurring incompatibilities (damage, mismatch, inconsistency) known to the accuracy of probability distribution?.

Designing and applying LPG installations has to include the conditions for ensuring their safe operation. At the design stage there is an obligation to manage the risk through its assessment and reduction. Risk reduction can be achieved using appropriate reliability structures and properly selected components ${ }^{\mathbf{1 0}}$. For pressure tanks used for propane-butane (LPG) storage, such element is a safety valve. Reliability of the safety valve is connected with the selection of the right producer, followed by an appropriate choice of the producer's series of types.

The main research goal of the study is the hazardous analysis of propane-butane gas outflow for the safety valve - LPG tank system. The additional goal is the development of an useful method to fast identify the hazard of a mismatched safety valve.

The results of the research analysis have confirmed that safety valves are the basic protection of the installation (tank) against failures that can lead to loss of life, material damage and further undesired costs of their unreliability. That is why a new, professional computer program has been created that allows for the selection of safety valves or for the verification of a safety valve selection in installations where any technical or technological changes have been made.

\section{INSTALLATION CHARACTERISTICS}

LPG gas distribution stations have a number of technical security devices ${ }^{11}$. One of them is the safety valve used to secure liquid LPG tank from damage caused by excessive pressure. Installation diagram is shown in Figure 1. 


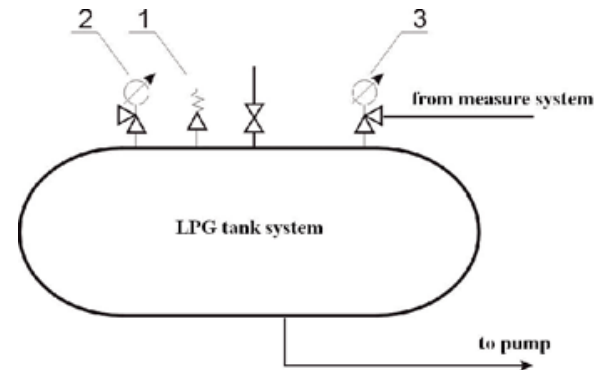

Figure 1. Diagram of the safety valve - LPG tank system: 1 - safety valve, 2 - percent level indicator, 3 - gas pressure manometer

\section{RISK ANALYSIS}

\section{Identification of threats}

The general risks of the petrol stations include:

- machines moving on the petrol station premises,

- chemicals, toxic, sensitizing substances,

- fire,

- explosion,

- changing weather conditions,

- outdated technology,

- contamination of soil and groundwater with petroleum products.

\section{Risks associated with the storage of LPG}

Liquefied LPG (propane-butane) has weak narcotic properties, and in high concentrations becomes suffocating. Direct contact with liquefied gas may cause burns. Propane-butane is stored in liquid state at increased pressure. Under normal conditions it becomes a combustible gas, heavier than the air, which could form explosive mixtures with it ${ }^{11}$. According to Directive 1999/45/EC and Regulation No 1272/2008 of the European Parliament and Council Regulation (EC), the basic physical and chemical properties of the gas are presented in Table 1.

To identify hazards, HAZOP (Hazard and Operability Studies) analysis has been applied. Table 2 shows the results of analysis of the hazards associated primarily with the safety valve.
Table 1. Basic physic-chemical properties ${ }^{\mathbf{1 2}}$

\begin{tabular}{|l|l|}
\hline $\begin{array}{l}\text { Shape, } \\
\text { structure } \\
\text { or design }\end{array}$ & liquefied gas, colorless \\
\hline Smell & Perceptible, ripe, unpleasant \\
\hline $\begin{array}{l}\text { Initial boiling } \\
\text { point }\end{array}$ & $-42,1^{\circ} \mathrm{C}$ (propane) \\
\hline Flash-point & $-95^{\circ} \mathrm{C}$ (propane) $-60^{\circ} \mathrm{C}$ (butane) \\
\hline $\begin{array}{l}\text { Flammability } \\
\text { (solid, gas) }\end{array}$ & Extremely flammable gas \\
\hline $\begin{array}{l}\text { Upper/lower } \\
\text { explosion limit }\end{array}$ & $\begin{array}{l}\text { The lower limit: } 1.9 \% \text { of volume for butane and } \\
8.5^{2} \% \text { of volume for butane and } 9.5 \% \text { by volume } \\
\text { for propane }\end{array}$ \\
\hline Vapor pressure & $\begin{array}{l}0.21 \mathrm{MPa} \text { at } 20^{\circ} \mathrm{C} \text { (butane); } 0.83 \mathrm{MPa} \text { at } 20^{\circ} \mathrm{C} \\
\text { (propane) }\end{array}$ \\
\hline Vapor density & Approx. $549 \mathrm{~kg} / \mathrm{m} 3$ at $15,6^{\circ} \mathrm{C}$ \\
\hline Relative density & Gas is heavier than the air \\
\hline $\begin{array}{l}\text { Temperature of } \\
\text { self-ignition }\end{array}$ & $365^{\circ} \mathrm{C}$ (butane), $470^{\circ} \mathrm{C}$ (propane) \\
\hline
\end{tabular}

\section{EMERGENCY SCENARIOS}

\section{Scenario 1. Gas outflow caused by human mistake during} the wrong selection of a safety valve

Percentage level indicator on the gas tank is damaged. While pumping gas from tanker to the tank, its overfilling took place. Due to inappropriately chosen safety valve, excessive pressure increase leading to permanent unsealing of the system has occurred. A considerable amount of gas flew out from the tank and formed a cloud that has been ignited. There was an explosion, which resulted in the injuring of three people, including one seriously. The tank has been permanently damaged.

\section{Scenario 2. Safety valve locking in the closed position}

In the autumn season, at night, at a temperature close to $0^{\circ} \mathrm{C}$ the tank has been filled from the tanker to a level of $85 \%$. During the next sunny day, by the action of heat, there was a significant increase in gas pressure in the tank because the safety valve jammed in the closed position. After opening the ball valve, allowing refueling vehicles, a flow of gas to the pipe connections has occurred. It resulted in unsealing of flange connection. Service saw an outflow of gas and closed the ball valve.

Table 2. HAZOP analysis

\begin{tabular}{|l|l|l|l|l|l|}
\hline No. & $\begin{array}{l}\text { Guiding } \\
\text { word }\end{array}$ & Deviation & Cause & Results \\
\hline 1. & Less & Lower level & Mechanical failure of the pipe connection & $\begin{array}{l}\text { Outflow of liquid propane-butane to } \\
\text { the environment }\end{array}$ & $\begin{array}{l}\text { Current control of the } \\
\text { technical condition }\end{array}$ \\
\hline 2. & Less & Lower level & $\begin{array}{l}\text { Unsealing pipeline with propane-butane due } \\
\text { to corrosion }\end{array}$ & $\begin{array}{l}\text { Outflow of liquid gas to the } \\
\text { environment }\end{array}$ \\
\hline 3 & More & $\begin{array}{l}\text { Higher } \\
\text { pressure }\end{array}$ & $\begin{array}{l}\text { Propane-butane temperature increase in } \\
\text { the tank due to its insolation }\end{array}$ & $\begin{array}{l}\text { Release into the atmosphere } \\
\text { through the safety valve }\end{array}$ \\
\hline 4. & More & $\begin{array}{l}\text { Higher } \\
\text { pressure }\end{array}$ & $\begin{array}{l}\text { Failure of gas level sensors during the filling } \\
\text { of tanks from the tanker }\end{array}$ & $\begin{array}{l}\text { Release through the safety valve } \\
-\end{array}$ & $\begin{array}{l}\text { Outflow of liquid propane-butane to } \\
\text { the environment }\end{array}$ \\
\hline 5. & Less & Lesser flow & Leak on a flexible connection & $\begin{array}{l}\text { Release into the atmosphere } \\
\text { through the safety valve }\end{array}$ & Fire protection system \\
\hline 6. & More & $\begin{array}{l}\text { Higher } \\
\text { pressure }\end{array}$ & External fire &
\end{tabular}


The gas from the tank with a broken safety valve has been pumped into the second reservoir. Due to the fast reaction of the service, there were no human losses. The costs of failure were mainly related to the replacement of the safety valve, installation sealing, and downtime.

\section{Scenario 3. Safety valve locking in an open position}

During the storage of LPG in the winter safety valve has been locked in the open position. The outflowing gas has been ignited, and as a result, there was a fire jet. Called the fire brigade extinguished the fire and secured the tank against further outflow. There were no casualties. The costs of failure resulted from the installation damage and fire fighting.

The application checking the selection of the safety valve for a gas tank.

The safety valve is a valve that opens automatically when the gas pressure exceeds a limit value. This prevents an excessive pressure increase and in extreme cases unsealing of the tank, which could lead to an explosion.

The application checks the correct selection of the valve to the tank and gives information of the type of valve parameters that should be changed in case of wrong selection (Fig. 2).

To determine correctly the capacity $(\mathrm{G})$ required for the gas tank and the capacity of the safety valve (m), at first, it is necessary to enter the data of the tank (green), then of the safety valve (blue). It is also necessary to choose a medium stored in the tank from a drop-down list (Fig. 3).

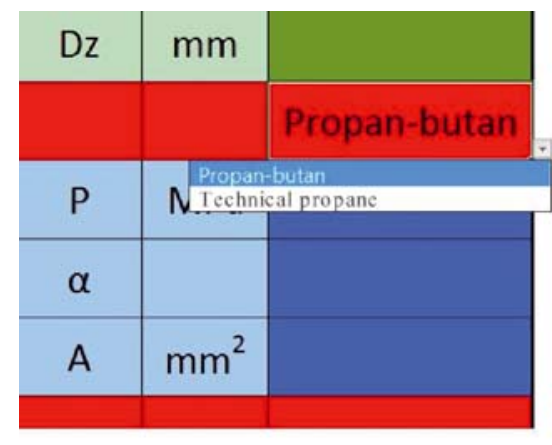

Figure 3. View of the drop-down list with the medium

After entering the technical data, the application will check whether the valve is selected properly or not. If the valve is properly chosen, the application in the line "Information about compatibility" displays the message: "Valve chosen correctly, because m> G" (Fig. 4).

If the valve is incorrectly chosen, application window command displays the information: "Valve chosen incorrectly, because $\mathrm{m}<\mathrm{G}-$ set a valve with a higher flow coefficient or larger flow surface".

In this case, the application will suggest the parameters of the valve that must be changed in order to get the correct final result.

\section{SUMMARY}

The analysis of literature relating to the obtaining energy from gas as well as threats regarding the use

\begin{tabular}{|c|c|c|c|}
\hline $\begin{array}{l}\text { Enter the tank and safety valve data } \\
\text { values }\end{array}$ & measure & $\begin{array}{l}\text { unit of } \\
\text { measure }\end{array}$ & value \\
\hline Total tank length & L & $\mathrm{mm}$ & \\
\hline Outer diameter of the tank & $\mathrm{Dz}$ & $\mathrm{mm}$ & \\
\hline Medium & & & Propane-butane \\
\hline Opening pressure & $\mathrm{p}$ & $\mathrm{MPa}$ & \\
\hline Coefficient of outflow & $\alpha$ & & \\
\hline Surface of the outflow & A & $\mathrm{mm}^{2}$ & \\
\hline \multicolumn{4}{|l|}{ Results: } \\
\hline Required bandwidth & G & $\mathrm{kg} / \mathrm{h}$ & 0 \\
\hline Capacity of the safety valve & $\mathrm{m}$ & $\mathrm{kg} / \mathrm{h}$ & 0 \\
\hline Information about compatibility & $\begin{array}{r}\text { Valve ch } \\
\text { - set } \\
\text { coeff }\end{array}$ & $\begin{array}{l}\text { en incorre } \\
\text { valve witl } \\
\text { ent or larg }\end{array}$ & $\begin{array}{l}\text { y, because } \mathrm{m}<\mathrm{G} \\
\text { higher flow } \\
\text { flow surface }\end{array}$ \\
\hline
\end{tabular}

Figure 2. View of the application checking the safety valve

\begin{tabular}{lccc}
$\begin{array}{l}\text { Enter the tank and safety valve } \\
\text { data values }\end{array}$ & measure & unit of measure & value \\
$\begin{array}{l}\text { Total tank length } \\
\text { Outer diameter of the tank }\end{array}$ & $\mathrm{L}$ & $\mathrm{mm}$ & 4310 \\
$\begin{array}{l}\text { Fuel } \\
\text { Opening pressure }\end{array}$ & $\mathrm{p}$ & $\mathrm{mm}$ & 1250 \\
$\begin{array}{l}\text { Coefficient of outflow } \\
\text { Surface of the outflow }\end{array}$ & $\alpha$ & & Propane-butane \\
Results: & $\mathrm{A}$ & $\mathrm{mm}^{2}$ & 1,56 \\
Required bandwidth & $\mathrm{G}$ & $\mathrm{kg} / \mathrm{h}$ & 433 \\
Capacity of the safety valve & $\mathrm{m}$ & $\mathrm{kg} / \mathrm{h}$ & 4548,4 \\
\hline
\end{tabular}

Information about compatibility $\quad$ Valve chosen correctly, because $\mathrm{m}>\mathrm{G}$

Figure 4. View of the application with information on the correct selection of the valve 
of gas tank and also material presented in this paper indicates that these issues are very important in terms of technical safety in everyday life ${ }^{13,14,15}$.

LPG, as a cheap fuel that provides a great savings in transport, is commonly used to supply of combustion engines. Therefore, the number of LPG tanks in small cars has increasing. The number of stations offering gas fuel has also increasing. This has led to the development of studies on quality of LPG fue ${ }^{14}$. Researchers are looking for new efficient technological solutions for gas supply systems ${ }^{\mathbf{1 6}}$.

It is also important to improve a safety of use of devices with LPG gas and liquied fuels, which requires the improvement of standards and regulations for quality and safety management systems ${ }^{17}$. Prediction and prevention the risks associated with LPG use makes it possible to reduce or even avoid accidents ${ }^{13,18}$. However, analysis of emergency scenarios, presented in this paper are not appreciated by scientists and pragmatists until there is accident with different effects. For these reasons, it was very important to develop the application that allows for the selection of safety valves or for the verification of a safety valve selection in installations where any technical or technological changes have been made.

The final concept of the authors will be the creation of a comprehensive model for LPG stations, enabling on theoretical safety analysis and hazard simulation and also their impact on surroundings. This model will allow to avoid danger situations connected with the utilization of different types of LPG gas tanks.

\section{CONCLUSIONS}

Safety valves are the primary protection of the system (tank) before failures, which can lead to loss of life, material damage, and further unwanted costs. Their reliability and correct selection is therefore essential.

Furthermore, in order to reduce the risk of tank overfilling it is recommended to use a double measurement of the gas inside.

It is also advised to use gas detectors, particularly where even a small amount of released gas could cause further threats.

Analyzes carried out for the LPG installation will be the basis for computer simulation of a technical safety for installations equipped with safety valves.

Simulation analyzes will contribute to the construction of the mathematical model for LPG tank equipped with a safety valve.

After the positive attempt to build the mathematical model of a system for a tank with a safety valve, effort will be taken to build a model of technological lines consisting of many discussed systems.

\section{LITERATURE CITED}

1. Szmigielski, M., Zarajczyk, J., Kowalczyk-Juśko, A., Kowalczuk, J., Rydzak, L., Ślaska-Grzywna, B., Krzysiak, Z., Cycan, D. \& Szczepanik, M. (2014) Quality of biomass briquettes as stock for thermochemical conversion and syngas production. Przem. Chem. 93(11), 1000-1004.

2. Krzysiak, Z., Bartnik, G., Samociuk, W., Zarajczyk, J., Plizga, K., Rachwał, B., Wierzbicki, S., Krzywonos, L. \& Brumercik F. (2017). Explosion hazard analysis at a liquid fuel stadion. Przem. Chem. 96(2), 1032-1035.
3. Łubowska, A. \& Nazar, N. (2015). The risk assessment of safe storage of liquid ammonia. Part 1, Storage in a pressurized spherical tank. Przem. Chem. 94(11), 1932-1935.

4. Łubowska, A. \& Nazar, N. (2015) The risk assessment of safe storage of liquid ammonia. Pt. 2, Storage in a vessel under pressure. Przem. Chem. 94(12), 2112-2016.

5. Regulation of the Minister of Economy of 10 october 2013 - Dz.U poz. 1479. (in Polish)

6. Law of 27 April 2001 on the Protection of the Environmental. Dz.U nr 62, poz. 6271. (in Polish)

7. Droździel, P. \& Krzywonos, L. (2009) The estimation of the reliability of the first daily diesel engine start-up during its operation in the vehicle. Eksploatacja i Niezawodność Maintenance and Reliabilit 1(41), 4-10.

8. Jedliński, Ł., Caban, J., Krzywonos, L., Wierzbicki, S. \&Brumerčík, F. (2015) Journal of Application of vibration signal in the diagnosis of IC engine valve clearance, Journal of Vibroenginee. 17(1) 175-181.

9. Bartnik, G., Pieniak, D., Niewczas, M., Niewczas, A. \& Marciniak, A. (2016) Probabilistic model for flexural strength of dental composites used in modeling reliability of the "tooth-dental composite" system. Eksploatacja i Niezawodność - Maintenance and Reliability 1(18), 136-141.

10. Samociuk, W., Krzysiak, Z., Szmigielski, M., Zarajczyk, J., Stropek, Z., Gołacki, K., Bartnik, G, Skic, A. \& Nieoczym, A. Modernization of the control system to reduce a risk of severe accidents during non-pressurized ammonia storage. Przem. Chem. 95(5), 1032-1035.

11. Rogalewicz, G. \& Bajdur, W.M.: Technique. Informatics. Security Engineering. Scientific Works of the Jan Długosz in Częstochowa t. II, 325-336 (in Polish).

12. http://radom24.pl/artykul/czytaj/23524 access 21.01.2016. (in Polish).

13. Paliwal, G., Agrawal, K., Srivastava, R.K. \& Sharma, S. (2014) Domestic liquefied petroleum gas: Are we using a kitchen bomb? Burns. J. Inter. Soc. Burn Injuries 40, 1219-1224.

14. Kai, J., Morganti, A., Tien Mun Foong, A., Michael, J., Brear, A., Gabriel da Silva, B., Yi Yang, A. \& Frederick, L. (2013). Dryer: The Research and Motor octane numbers of Liquefied Petroleum Gas (LPG). Fuel. Sci. Technol. Fuel Energy 108 797-811.

15. Andadari, R.K., Mulder, P. \& Rietveld, P.: Energy poverty reduction by fuel switching. Impact evaluation of the LPG conversion program in Indonesia. Energy Policy Inter. J. Polit., Eco., Plan., Environ. Soc. Asp. Energy 66, 436-449

16. Raslavičius, L., Keršys, A., Mockus, S., Keršienè, N. \& Starevičius, M. (2014) Liquefied petroleum gas (LPG) as a medium-term option in the transition to sustainable fuels and transport. Renew. Sustain. Energy Rev. 32, 513-525

17. Bartnik, G., Krzysiak, Z., Samociuk, W., Łysiak, G., Plizga, K., Szmigielski, M., Nieoczym, A., Kaliniewicz, Z. \& Brumercik F. (2017) Documentation of meeting the requirements in the area of technical safety on the example of distribution of liquid fuels. Przem. Chem. 96(5), 1039-1041.

18. Samociuk, W., Krzysiak, Z., Bartnik, G., Skic, A., Kocira, S., Rachwał, B., Bąkowski, H., Wierzbicki, S. \& Krzywonos, L. (2017) Analysis of explosion hazard on propane-butane liquid gas distribution stations during self-tankage of vehicles. Przem. Chem. 96/4, 874-879. 